\title{
Results of surgical treatment for patients with a spinal angioma
}

\author{
VAlEntine LOGUE, M. J. AMINOFF, AND B. E. KENDALL \\ From the National Hospitals for Nervous Diseases, Maida Vale Hospital, \\ and the Institute of Neurology, Queen Square, London
}

SYNOPSIS The clinical, angiographic, and operative findings in 16 patients with a spinal angioma are reviewed, and the results of surgery are assessed. The surgical procedure employed in 15 patients consisted of excision of the fistulous portion of the malformation, achieved by intradural ligation of $\vec{\circ}$ its feeding vessels and excision of its draining veins throughout the limits of the exposure. In 14 patients, a previously progressive deterioration in their clinical condition was arrested by surgical correction of the malformation and in 12 of these patients there was worthwhile improvement in functional capacity. The optimal time for surgical treatment is considered and suggestions are made for the manner in which patients should be investigated.

There has been a recent resurgence of interest in patients with spinal angiomas, due to refinements in neuroradiological techniques which have led to a more active approach to their surgical management. We have recently reviewed the clinical features of a large group of patients with this disorder and defined the natural history and prognosis in 60 untreated cases (Aminoff and Logue, 1974a, b). It seemed an appropriate time, therefore, to assess the results of corrective surgery in such patients.

Spinal angiomas are vascular malformations, presumably congenital in nature, which consist of an anomalous intradural, but usually extramedullary, arteriovenous fistula. They are more common in males than females. The onset of symptoms is usually delayed until middle-age when a progressive paraparesis and paraparaesthesis develop, with early derangement of bowel and bladder function (Aminoff and Logue, 1974a). There is no satisfactory medical treatment of the anomaly. There have been a number of recent publications concerning the results of surgical treatment, but in most of these only limited clinical details are provided; accordingly, it is often difficult to assess satisfactorily either the benefits of surgery with respect to the functional capacity of patients, or the surgical morbidity. For this reason, we have analysed in detail the response of a series of patients to suP gical treatment, and have defined the manner in 을 which we believe future patients should be $\vec{c}$ investigated and managed.

\section{METHODS}

Fourteen of the patients in our earlier series (Amino and Logue, 1974a) were operated upon by one of us 6 (V.L.) and form the subject matter of this report. Two $\perp$ other patients who presented here more recently and who came to operation have also been included.

The response to operation has been assessed by reference both to the symptoms and signs, and to the functional capacity of patients. The symptoms and signs are considered in terms of overall motor, sensory, and sphincter disturbance, rather than in a more detailed manner which would have necessitated the use of a cumbersome scoring system. Even in such broad terms, however, their relationship to functional disability may be indirect and tenuous. Since the more important parameter to the patient is clearly that of functional capacity, we have preferred to study this in greater detail.

We have rated functional capacity in the manner of our earlier study (Aminoff and Logue, 1974b) but, for convenience, the appropriate definitive criteria are recapitulated in Table 4.

Seven of these patients had continued to attend here regularly for follow-up. One of the remaining patients had attended for follow-up at another hospital until his death, and his notes were kindly 
TABLE 1

CLINICAL FEATURES

\begin{tabular}{|c|c|c|c|c|c|c|c|c|}
\hline \multirow[t]{2}{*}{ Case no. } & \multirow{2}{*}{\multicolumn{2}{|c|}{$\begin{array}{l}\operatorname{Agc}(y r) \\
\operatorname{sex}\end{array}$}} & \multirow{2}{*}{$\begin{array}{c}\text { Symptoms } \\
\text { (in order of } \\
\text { onset) }\end{array}$} & \multirow{2}{*}{$\begin{array}{c}\text { Leg } \\
\text { weakness }\end{array}$} & \multicolumn{3}{|c|}{ Signs, sensation impaired } & \multirow[t]{2}{*}{ Comments } \\
\hline & & & & & Superficial & $J P S$ & $V i b$ & \\
\hline $\begin{array}{l}1 \text { T.A. } \\
\text { (A50782) }\end{array}$ & 64 & $\mathbf{M}$ & S M I Sp & $\mathbf{R}>\mathbf{L}$ & L4-S5 & + & + & \\
\hline $\begin{array}{l}2 \text { C.B. } \\
\text { (A48639) }\end{array}$ & 47 & $\mathbf{M}$ & M Sp S & $\mathbf{R}=\mathbf{L}$ & L2-S5 & + & + & Symptoms aggravated by exercise \\
\hline $\begin{array}{l}3 \text { J.B. } \\
\text { (67589) }\end{array}$ & 63 & $\mathbf{M}$ & M S Sp I & $\mathbf{R}<\mathbf{L}$ & T10-S5 & + & + & $\begin{array}{l}\text { Symptoms aggravated by exercise and } \\
\text { certain postures }\end{array}$ \\
\hline $\begin{array}{l}4 \text { W.B. } \\
\text { (A26156) }\end{array}$ & 63 & $\mathbf{M}$ & Sp S M I & $\mathbf{R}=\mathbf{L}$ & T11-S5 & + & + & Symptoms aggravated by exercise \\
\hline 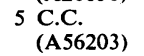 & 60 & $\mathbf{M}$ & S M Sp & $\mathbf{R}<\mathbf{L}$ & T12-S5 & - & + & $\begin{array}{l}\text { Symptoms aggravated by certain } \\
\text { postures }\end{array}$ \\
\hline 6 S.C. & 64 & $\mathbf{M}$ & S I Sp M & $\mathbf{R}=\mathbf{L}$ & T6-S5 & + & + & Symptoms aggravated by exercise \\
\hline $7 \begin{array}{l}\text { A.D. } \\
\text { (A53748) }\end{array}$ & 58 & $\mathbf{M}$ & S M Sp I & $\mathbf{R}=\mathbf{L}$ & L5-S5 & - & + & \\
\hline 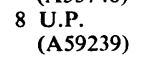 & 33 & $\mathbf{F}$ & $\mathbf{S} \mathbf{M} \mathbf{S p}$ & $\mathbf{R}=\mathbf{L}$ & S1-S5 & - & - & $\begin{array}{l}\text { Symptoms related to pregnancy and } \\
\text { certain postures }\end{array}$ \\
\hline $\begin{array}{l}9 \text { J.DeQ. } \\
\text { (A55886) }\end{array}$ & 55 & $\mathbf{M}$ & S M Sp I & $\mathbf{R}>\mathbf{L}$ & T8-S5 & + & + & \\
\hline $\begin{array}{l}10 \text { N.S. } \\
\text { (A63384) }\end{array}$ & 55 & $\mathbf{M}$ & M Sp S & $\mathbf{R}=\mathbf{L}$ & L2-S5 & + & + & $\begin{array}{l}\text { History of preceding trauma. Symptoms } \\
\text { aggravated by exercise }\end{array}$ \\
\hline $\begin{array}{l}11 \text { E.S. } \\
\text { (A35108) }\end{array}$ & 53 & M & S Sp M & $\mathbf{R}<\mathbf{L}$ & S1-S5 & - & + & $\begin{array}{l}\text { Symptoms aggravated by certain } \\
\text { postures }\end{array}$ \\
\hline $\begin{array}{l}12 \text { D.T. } \\
\text { (A28642) }\end{array}$ & 44 & $\mathbf{M}$ & S I M Sp & $\mathbf{L}$ & S1-S5 & + & + & Partial Brown-Séquard syndrome \\
\hline $\begin{array}{l}13 \text { W.W. } \\
\text { (A67666) }\end{array}$ & 50 & $\mathbf{M}$ & $\mathbf{S} \mathbf{M} \mathbf{S p}$ & $\mathbf{R}=\mathbf{L}$ & T10-S5 & + & + & $\begin{array}{l}\text { History of preceding trauma; symptoms } \\
\text { aggravated by exercise, certain } \\
\text { postures and administration of } \\
\text { ACTH }\end{array}$ \\
\hline 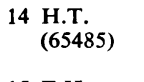 & 58 & $\mathbf{M}$ & $\begin{array}{l}\text { Myoclonic } \\
\text { jerking } \\
\text { M Sp }\end{array}$ & $\begin{array}{c}\mathbf{L} \\
\text { (and } \mathrm{L} \text { arm) }\end{array}$ & T2-S5 & + & + & $\begin{array}{l}6 \text { subarachnoid haemorrhages in pre- } \\
\text { ceding } 17 \text { years }\end{array}$ \\
\hline $\begin{array}{l}15 \text { E.H. } \\
\text { (A70782) }\end{array}$ & 73 & $\mathbf{F}$ & M Sp S & $\mathbf{R}<\mathbf{L}$ & T9-S5 & + & + & \\
\hline $\begin{array}{l}16 \text { T.W. } \\
\text { (76499) }\end{array}$ & 51 & $\mathbf{M}$ & S M Sp I & $\mathbf{R}>\mathbf{L}$ & T12-S5 & + & + & Symptoms aggravated by exercise \\
\hline
\end{tabular}

M: motor disturbance; S: sensory disturbance; Sp: sphincteric disturbance; I: impotence; JPS: joint position sense; Vib; vibration sense.

made available to us. The other eight patients were seen here by one of us (M.J.A.) for the purpose of this study.

\section{RESULTS}

The clinical data relating to the preoperative state of our patients (Table 1) indicate that the majority of patients were middle-aged males (Aminoff and Logue, 1974a). In several cases symptoms were related to preceding trauma, or aggravated by exercise or certain postures. Most patients had a combination of motor, sensory, and sphincter disturbances (Tables 1 and 4). In all 16 patients clinical examination suggested that there was a severe disturbance of function in the spinal cord.

MYELOGRAPHY In all cases, myelography showed characteristic, tortuous filling defects due to elongated, distended veins. In four patients these vascular impressions converged upon an area which was subsequently shown angiographically to be the site of the anomalous shunt, and in some instances a small projection from the cord shadow was visible in this position (Figure, a). In two patients (cases 5 and 8) a feeding artery to the angioma was tentatively recognized at myelography - confirmation being obtained angiographically-as a linear shadow running toward the cord from the side of the theca near the exit of a nerve root. Myelography was followed by temporary exacerbation of leg weakness in case 4 , but no other sequelae occurred when performed here.

AORTOGRAPHY Aortography was performed in three of the earlier patients in an attempt to 


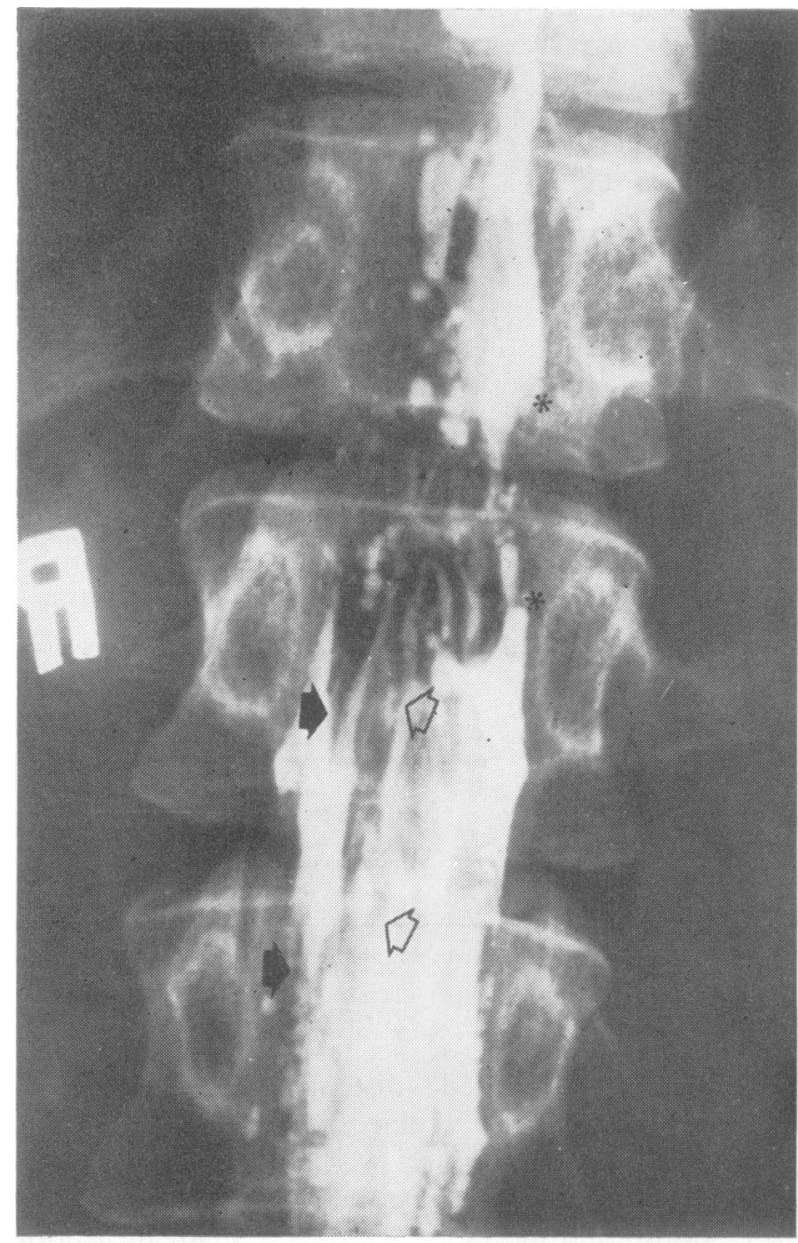

(a)

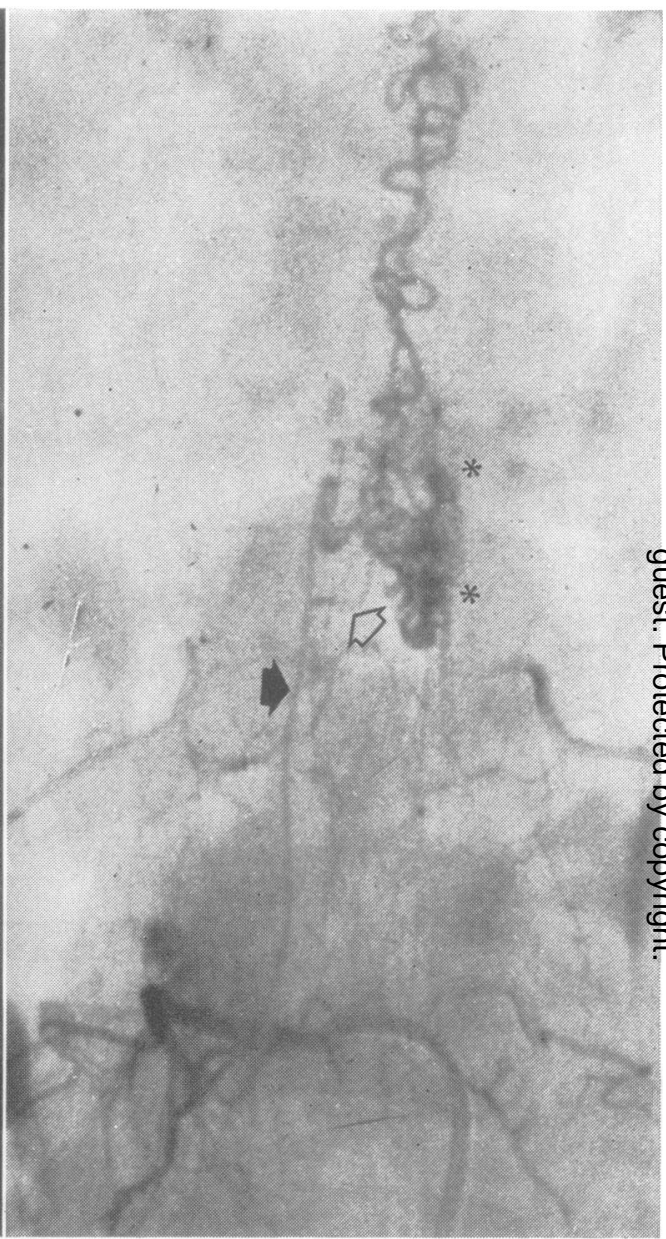

(b)

FIGURE Case 8. (a) Myelogram, prone film. The feeding artery (black arrows) and descending vein (hollow arrows) are outlined. These vessels converge towards a constant defect (asterisks) caused by the nidus of vessels in the region of the shunt. The theca above the shunt is incompletely filled but draining veins are partly outlined in this region also. (b) Spinal angiogram, selective injection of right 2nd lumbar artery. The feeding artery (black arrow) ascends along the right side of the theca to D12-L1 vertebral level before crossing the mid-line to supply the shunt (asterisks). Draining veins mainly ascend, but a fairly large descending vein is indicated (hollow arrow). 
TABLE 2

ANGIOGRAPHIC FEATURES

\begin{tabular}{|c|c|c|c|c|c|c|}
\hline \multirow{2}{*}{$\begin{array}{l}\text { Case } \\
\text { no. }\end{array}$} & \multirow{2}{*}{$\begin{array}{l}\text { Upper level of } \\
\text { clinical signs } \\
\text { (corresponding } \\
\text { vertebral level) }\end{array}$} & \multicolumn{2}{|c|}{ Shunt at angiography } & \multirow[t]{2}{*}{ Feeding arteries } & \multirow{2}{*}{$\begin{array}{l}\text { Direction of } \\
\text { venous drainage }\end{array}$} & \multirow{2}{*}{$\begin{array}{l}\text { Local radicular } \\
\text { branch to } \\
\text { anterior spinal } \\
\text { artery }\end{array}$} \\
\hline & & $\begin{array}{l}\text { Vertebral } \\
\text { level }\end{array}$ & Site & & & \\
\hline 1 & L4 (D11) & D11 & $\mathbf{R}$ posterolateral & R subcostal & Rostral & L 2nd lumbar \\
\hline 2 & L2 (D10) & D7-8 & $\mathbf{R}$ posterolateral & R 8th intercostal & Rostral & R 10th intercostal \\
\hline 3 & D10 (D7-8) & D6 & $\mathbf{R}$ posterolateral & R 6th intercostal & Rostral and caudal & L 9th intercostal \\
\hline 5 & D12 (D9) & D10 & Posterior & L subcostal & Rostral and caudal & L 10th intercostal \\
\hline 6 & D6 (D4) & D6-7 & Posterior & $\begin{array}{l}\text { R 7th intercostal } \\
\text { (R 8th intercostal) }\end{array}$ & Rostral & L 9th intercostal \\
\hline 7 & L5 (D12) & D9-10 & Posterior & R 9th intercostal & Caudal & L 11th intercostal \\
\hline 8 & S1 (L1) & D12-L1 & $\begin{array}{l}\text { L posterior extending } \\
\text { anteriorly }\end{array}$ & $\begin{array}{l}\text { R 2nd lumbar } \\
\mathbf{L} \text { 10th intercostal }\end{array}$ & Rostral & L subcostal \\
\hline 9 & D8 (D5-6) & D4 & Posterior & $\vec{R} 4$ th intercostal & Rostral and caudal & R 8th intercostal \\
\hline 10 & L2 (D10) & D7 & Posterior & $\begin{array}{l}\text { R 8th intercostal } \\
\text { (R 7th intercostal) }\end{array}$ & Caudal & Failed to fill \\
\hline 13 & D10 (D7-8) & D10 & L posterolateral & L 11 th intercostal & Rostral & L 10th intercostal \\
\hline 14 & C6-7 (C6) & C5-6 & Mainly posterior & $\begin{array}{l}\text { L \& } R \text { deep cervical } \\
\text { via } L \text { C6-7, R C5-6 } \\
\text { \& R T1-2 i.v. spaces }\end{array}$ & Rostral & L vertebral \\
\hline 15 & D9 (D6-7) & D9 & $\mathbf{R}$ posterolateral & $\begin{array}{l}\text { R 8th intercostal } \\
\text { (R 9th intercostal) }\end{array}$ & $\begin{array}{l}\text { Mainly rostral, } \\
\text { some caudal }\end{array}$ & L 7 th intercostal \\
\hline 16 & D12 (D9) & D9 & $\mathbf{R}$ posterolateral & $\begin{array}{l}R \text { 9th intercostal } \\
\text { (R 8th intercostal) }\end{array}$ & Rostral & L 10 th intercostal \\
\hline
\end{tabular}

Cases 4,11 , and 12 were investigated by aortography and have therefore been omitted from this Table.

Feeding vessels providing a secondary supply to the angioma are placed in parentheses.

visualize the malformation. No abnormality was seen in case 11 , while in case 12 there was some filling of the malformation but the vascular supply to it could not be identified with certainty. In case 4 , tortuous vessels were identified to the left of the theca at the 11 th thoracic vertebral level, but again it was not possible to identify clearly the segmental feeding arteries. One patient (case 12) developed flexor and adductor spasms of the leg with each injection of contrast material, but there was no change in his motor or sensory signs.

SELECTIVE SPINAL ANGIOGRAPHY In 12 patients, selective spinal angiography with opacification of all segmental arteries permitted the angioma and its feeding vessels to be visualized (Table 2; Figure, b). The angioma was situated at or below the level of the 6 th thoracic vertebra, corresponding approximately to a level at or below the 8 th thoracic segment of the spinal cord, in most cases. In several instances, however, the level at which clinical signs were present differed by up to two or three segments from the level of the malformation. The angioma was supplied by only a single segmental feeding vessel in seven of the 12 cases. In five patients, two feeding arteries were identified, and in all but one case they originated in adjacent intercostal vessels. The local radicular branch to the anterior spinal artery was not involved in feeding the malformation in any of our patients. The angiographic procedure was followed by a transient clinical deterioration in three patients; there was an increase in the sphincter disturbance of case 5 , in the leg weakness of case 9, and in the weakness, sensory, and sphincter disturbances of case 3 .

In case 14, bilateral vertebral and subclavian angiography was performed in view of the clinical and myelographic localization of the malformation to the cervical region. This provided information essential to the planning of corrective surgery (Table 2 ).

SURGERY In the 12 patients in whom the malformation was defined by selective spinal angiography, its localization was confirmed at operation. In cases 8,10 , and 15 , only one segmental feeding vessel was identified at operation, although two were demonstrated angiographically (Table 3). However, no extradural search was made and it may be that the two feeding vessels united in this region to form a single vessel penetrating the dura mater to supply the malformation, as was demonstrated in case 16 . Temporary clamping of the feeding vessel resulted in a reduction in bulk or pulsation of the malformation and/or darkening in colour of the 
TABLE 3

OPERATIVE FINDINGS

\begin{tabular}{|c|c|c|c|c|}
\hline \multirow{2}{*}{$\begin{array}{l}\text { Case } \\
\text { no. }\end{array}$} & \multicolumn{2}{|c|}{ No. of segmental feeders } & \multirow{2}{*}{$\begin{array}{c}\text { Source of } \\
\text { feeding vessels }\end{array}$} & \multirow{2}{*}{$\begin{array}{c}\text { Intra- } \\
\text { medullary } \\
\text { component }\end{array}$} \\
\hline & $\begin{array}{l}\text { at selective } \\
\text { angiography }\end{array}$ & $\begin{array}{c}\text { at } \\
\text { operation }\end{array}$ & & \\
\hline 1 & 1 & 1 & Posterior & 0 \\
\hline 2 & i & 1 & Posterior & $\mathbf{0}$ \\
\hline 3 & 1 & 1 & Posterior & 0 \\
\hline 4 & NP & 2 & Anterior and posterior & 0 \\
\hline 5 & 1 & 1 & $\begin{array}{l}\text { Posterior (accessory } \\
\text { brs. from anterior) }\end{array}$ & 0 \\
\hline 6 & 2 & 2 & Posterior & $\mathbf{0}$ \\
\hline 7 & 1 & 1 & Posterior & 0 \\
\hline 8 & 2 & 1 & Anterior & + \\
\hline 9 & 1 & 1 & Posterior & 0 \\
\hline 10 & 2 & 1 & Posterior & 0 \\
\hline 11 & NP & & None identified & + \\
\hline 12 & NP & 1 & Posterior & + \\
\hline 13 & 1 & 1 & Posterior & 0 \\
\hline 15 & 2 & 1 & Posterior & $\mathbf{0}$ \\
\hline 16 & 2 & 2 & Posterior & 0 \\
\hline
\end{tabular}

NP: not performed.

In cases 4,11 , and 12, aortography was undertaken, but the segmental arteries feeding the malformation were not visualized.

Laminectomy was not performed in case 14 who has therefore been omitted from this table.

The source of the feeding vessel was determined in each case by the location of the nerve root it accompanied. blood contained within it, in 11 of the 12 patients in whom this manoeuvre was performed, but such changes were sometimes slow to develop, as noted previously by Ommaya et al. (1969). In three patients the presence of an intramedullary component of the malformation was implied by local swelling of the cord, with vessels emerging from it to connect with the extramedullary vessels comprising the malformation (Table 3).

The surgical procedure adopted was intradural ligation of the vessel or vessels feeding the angioma, combining their removal with excision of the fistulous communication and its enlarged draining veins throughout the length of the exposure which usually extended over three laminae. The dissecting microscope has facilitated the technical aspects of excising the malformation.

This procedure was used in all patients except case 14 in whom the malformation was fed by the deep cervical arteries; they were easily accessible to extravertebral ligation and the malformationf itself was not excised in view of the rapid im풍

TABLE 4

RESPONSE TO SURGICAL TREATMENT

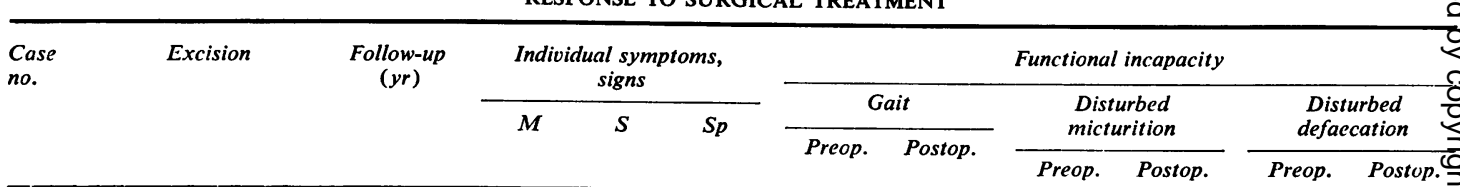

\begin{tabular}{|c|c|c|c|c|c|c|c|c|c|c|c|}
\hline 1 & Complete & 44 & + & + & 0 & 2 & 1 & 1 & 1 & 1 & 1 \\
\hline 2 & Complete & $4 \frac{1}{2}$ & + & + & + & 5 & 4 & 3 & $2-3$ & 2 & i \\
\hline 3 & Complete & 2 & + & + & 0 & 5 & 4 & 3 & 3 & 2 & 2 \\
\hline 4 & Complete & $5 \frac{1}{2}$ & + & + & 0 & 5 & 4 & 3 & 3 & 2 & 2 \\
\hline 5 & Incomplete* & $2 \frac{1}{2}$ & + & 0 & + & 3 & 2 & 1 & $\mathrm{~N}$ & 1 & 1 \\
\hline 6 & Complete & 2 & + & + & 0 & 4 & 4 & 2 & 2 & 2 & 2 \\
\hline 7 & Complete & $3 \frac{1}{4}$ & + & + & 0 & 3 & 2 & 3 & 3 & 2 & 2 \\
\hline 8 & Incomplete $†$ & 3 & + & 0 & + & 3 & 1 & 3 & $\mathbf{N}$ & 3 & 1 \\
\hline 9 & Complete & 2 & + & + & - & 2 & 1 & $1-2$ & 2 & 1 & 2 \\
\hline 10 & Complete & $1 \frac{1}{2}$ & - & + & 0 & 3 & 4 & 1 & $\overline{1}$ & 1 & $\mathbf{N}$ \\
\hline 11 & Incomplete & 7 & + & + & + & 2 & 1 & 1 & $\mathbf{N}$ & 1 & $\mathbf{N}$ \\
\hline 12 & Incomplete† & 3 & - & - & - & $\overline{1}$ & 4 & 1 & 2 & 2 & 1 \\
\hline 13 & Complete & $\frac{1}{2}$ & + & + & + & 4-5 & 2 & 2 & 1 & 1 & 1 \\
\hline 14 & $\begin{array}{l}\text { Not performed (feeding } \\
\text { vessels ligated extra- }\end{array}$ & & & & & & & & & & \\
\hline & vertebrally) $\ddagger$ & 5 & + & + & + & 1 & $\mathbf{N}$ & 1 & $\mathbf{N}$ & $\mathbf{N}$ & $\mathbf{N}$ \\
\hline 15 & Complete & $\frac{3}{4}$ & + & 0 & + & 5 & $4-5$ & 3 & 2 & $\mathbf{N}$ & $\mathbf{N}$ \\
\hline 16 & Complete & $\frac{1}{2}$ & + & + & + & 4 & 3 & 3 & 1 & 3 & 1 \\
\hline
\end{tabular}

Symptoms and signs

+ : improved; 0: no change; - : worse; M: motor deficit; S: sensory deficit; Sp: sphincter disturbance.

Functional disturbances

N: normal.

Gait: 1 -onset of leg weakness, abnormal stance or gait, without restriction of activity; 2-restricted activity; 3-requires one stick or some support for walking; 4-requires crutches or two sticks for walking; 5-unable to stand, confined to bed or wheelchair.

Micturition: 1-mild-hesitance, urgency or frequency; 2-moderate-occasional urinary incontinence or retention; 3-severe-total urinary incontinence or persistent retention.

Defaecation: 1-mild-constipation; 2-moderate-occasional faecal incontinence or severe intractable constipation; 3-severe-total faecal incontinence.

The postoperative incapacity indicated relates to the condition of patients at the time of their last follow-up assessment.

* Case 5-anterior extension of angioma left in situ.

+ Cases 8, 11, 12-intramedullary component of angioma left in situ.

‡ Case 14-myoclonic jerking now settled completely. 
provement that followed these initial surgical procedures. In one patient (case 15) an attempt was made to occlude the feeding vessels to the angioma by embolization with gelfoam. One of the two feeding vessels was completely occluded thereby but the other remained patent. Moreover, when the angiographic studies were repeated 24 days later, it was clear that both vessels were again feeding the malformation, and accordingly the patient was operated upon in our usual manner.

RESULTS OF SURGERY The response to surgical treatment is indicated in Table 4. The majority of patients were moderately or severely disabled before surgery. Nevertheless, in all but two of the 16 cases, treatment led to arrest of a previously progressive course.

No severely incapacitated patient regained a normal gait. The functional disturbance in the legs improved by one grade in ten patients, and by two grades in two patients (cases 8 and 13) who were operated upon relatively soon after their gait disturbance had become severe, and presumably, therefore, before damage to the spinal cord had become irreversible.

Control of micturition improved in seven patients, in four of whom it returned to normal. Disturbances of defaecation similarly became milder in six patients. In two patients (cases 8 and 16) there was a marked improvement in the severe disturbance of both micturition and defaecation which each had developed before surgery. There was otherwise little correlation between changes in the control of micturition and defaecation as a result of surgery.

It is of some importance to consider the possible causes for the continued decline that occurred in two patients. In case 12 , the malformation was excised but an intramedullary component was left undisturbed. This patient initially showed improvement in motor and sphincter disturbances, but about two months after surgery there was an abrupt increase in all his symptoms which then gradually worsened over the following three years until his death. In view of its time course, it seems reasonable to attribute this deterioration to the intramedullary component of the angioma, rather than to the effects of surgery. In case 10 , reduction in functional capacity followed immediately after operation and he now requires two sticks instead of one for walking. This deterioration, which has not progressed, presumably relates to the operation itself.

Postoperative angiography was performed in only one of our cases, but showed the malformation to have been obliterated completely.

\section{DISCUSSION}

Until comparatively recently, attempts to treat patients with a spinal angioma by surgery were usually futile and, in some cases, led to increased functional disability. In particular, the results of decompressive surgery were disappointing. It had accordingly been our policy to delay operation until patients were severely incapacitated and, as a consequence, the majority of patients reported here were moderately or severely disabled, and were continuing to deteriorate, at the time of treatment. A more active approach to the management of such patients has been fostered by recent developments in neuroradiology which have permitted the accurate preoperative delineation of these malformations and their feeding vessels. The results of such active surgical treatment in our patients indicate that worthwhile improvement in the functional capacity and symptoms can be expected after excision of the angioma. Furthermore, we anticipate that even greater improvement will follow operation at an earlier stage in the natural history of the disorder, when the degree of irreversible damage to the spinal cord will be less marked.

It is important to consider our findings in relation to those of others. Shephard (1963, 1965) treated 11 patients by excision of the malformation without preoperative angiographic delineation. While the result of treatment is indicated, the criteria used in its evaluation are not provided and insufficient data are presented to permit independent assessment. Patients judged to have shown a 'good' result in that author's series were those in whom the disability was present for only a few weeks and in whom some degree of spontaneous improvement might have been anticipated (Aminoff and Logue, 1974b). Krayenbühl et al. (1969) reported a series of 17 patients treated by surgical excision of the malformation. As in our series, the 
majority of patients were male, and the malformation was located in the thoracic or lumbosacral regions, save in one case. These authors provide no details of the durations of follow-up in their cases, and-perhaps because angiography was not used routinely to localize the site of the fistulous shunt-attempted a total excision of the enlarged draining veins after laminectomy which often extended over six or more vertebrae. Moreover, the results of surgery were judged to be 'excellent' in patients who had little or no preoperative deficit and in whom the malformation was removed without incurring any significant increase in deficit. This clearly implies an evaluation of surgical morbidity rather than the effect of excision on the natural history of the condition. For these reasons, we consider that this study is not entirely satisfactory in permitting an independent assessment of the results of surgery.

Kunc and Bret (1969) reported a series of nine patients treated either by excision of the malformation or by ligation of feeding vessels, but insufficient data are provided of the pre- and post-operative functional capacities of individual patients to permit adequate assessment of their surgical results. Various surgical procedures were also employed by Djindjian et al. (1969) in the treatment of 29 patients, complete excision being undertaken in 19 instances. Twelve of these patients showed some improvement but it is difficult to assess the significance of this, in the absence of further clinical details; the other seven, who were completely paraplegic before surgery, showed no meaningful response to treatment.

Ommaya et al. (1969) have treated 11 patients by intradural ligation of all feeding vessels, without excision of the fistula: there was symptomatic improvement in all cases but one, in whom, however, insufficient time had elapsed for adequate assessment. In at least five of these patients there was significant improvement in gait disturbance.

We are unaware of a follow-up study on the more long-term prognosis of surgically treated patients with spinal angioma. It is, therefore, difficult to ascertain whether intradural ligation of feeding vessels is, in itself, as satisfactory a form of treatment as when combined with excision of the malformation. Moreover, the point would not be satisfactorily resolved by a comparison of the results gained in different centres since individual differences in surgical skill and postoperative paramedical care might lead to bias. In view of the possibility that feeding vessels, unrecognized at angiography or operation, may be left undisturbed and continue to supply the malformation-as in one of the 'incompletely treated' patients of Ommaya et al. (1969) - we believe that concomitant excision of the fistulous anomaly is the more satisfactory procedure.

INDICATIONS FOR SURGERY We have recently considered in detail the natural history of 60 untreated patients with spinal angioma (Aminoff and Logue, 1974b). Patients may remain asymptomatic for years, but once symptoms develop they may progress with great rapidity. Thus, within six months of the development of any functional impairment in the legs, $19 \%$ of patients were either confined to bed or require $\$$ two sticks/crutches for walking, and a similar $\overrightarrow{0}$ degree of disability had developed in $50 \%$ o모 patients by three years. However, in othef 은 patients the disability remained mild for man $\mathbb{B}-$ years after the development of symptoms. IQ $\mathbb{D}$ view of these observations, we suggested that the rapidity of progression in neurological deficit an 3 incapacity provides a useful guide to the most appropriate time for surgical correction of the $\vec{e}$ vascular anomaly; in cases with a slow rate of progression, however, treatment may become mandatory when the cumulative disability becomes restrictive.

MYELOGRAPHY The diagnosis of spinal angioma is suggested by myelography which is best undertaken with a large volume of positive contrast material and performed with the patient both prone and supine. Tortuous filling defects, due mainly to elongated distended veins and occurring without evidence of tumour or obstruction, are characteristic, but larger filling defects due to aneurysmal distension of veins, or partial obstruction due to arachnoiditis, may occur occasionally. As indicated above, the site of the fistula may sometimes be indicated by myelography from the manner in which vascular impressions converge upon it, and in such instances there may be a smooth projection from the cord shadow, caused by the vessels forming 
the shunt itself. It may also be possible to recognize tentatively a feeding artery extending toward the cord from the side of the theca near a nerve root. These additional features are helpful in planning selective angiography which, however, is best delayed until surgical treatment is contemplated.

SELECTIVE ANGIOGRAPHY It has been our usual practice at angiography to opacify all the segmental feeding vessels to the spinal cord. However, the reappraisal occasioned by this study suggests that a more limited approach would be adequate. The clinical and myelographic data in individual cases should determine which vessels are injected first. If a vessel is located which feeds the malformation without implicating the anterior spinal artery, we suggest that the three segmental arteries above and below it, and the corresponding contralateral vessels, are injected; in the majority of cases, this will localize any similar vessel feeding the malformation. In the cervical region, because the segmental vessels are modified during foetal development, the thyro- and costa-cervical trunks, and the vertebral arteries should be injected. In the planning of corrective surgery, it is important also to localize the anterior radiculo-medullary artery supplying the anterior spinal artery in the region of the shunt, as it may also be implicated in the fistulous malformation-a relatively uncommon occurrence in our experience-and to define its relationship to the proposed operative field. If the anterior spinal artery supplies an angioma which is located several segments away from the main segmental contribution to this vessel, the segmental arteries in the vicinity of the fistula must also be visualized. Accordingly, we suggest that the angiographic procedure is continued until this has been achieved and then is terminated.

We propose to perform such angiographic studies, which, though limited in scope, nevertheless provide all the information required in planning elective surgery, in the management of future patients. The only exception to this rule is an angioma in the lumbar region, in the investigation of which all lumbar and lateral sacral vessels below the shunt should be visualized, as ascending feeding vessels are not uncommon in such cases. The operation site itself will be determined by the angiographic findings, since, as indicated above, there may be a discrepancy of several segments between the clinical and radiological location of the malformation. Postoperative angiography, limited to showing that the aims of surgical treatment have been achieved, was performed in only one of our patients, but we suggest that this should be performed routinely, since the information it provides may be of prognostic significance.

\section{CONCLUSION}

In our series of 16 patients deterioration attributable to surgery occurred in one patient, a previously progressive course was arrested in 14 patients, and worthwhile improvement in functional capacity occurred in 12 of them.

\section{REFERENCES}

Aminoff, M. J., and Logue, V. (1974a). Clinical features of spinal vascular malformations. Brain, 97, 197-210.

Aminoff, M. J., and Logue, V. (1974b). The prognosis of patients with spinal vascular malformations. Brain, 97, 211-218.

Djindjian, R., Houdart, R., and Hurth, M. (1969). Les Angiomes de la Moelle. Sandoz: Paris.

Krayenbühl, H., Yaşargil, M. G., and McClintock, H. G. (1969). Treatment of spinal cord vascular malformations by surgical excision. Journal of Neurosurgery, 30, 427-435.

Kunc, Z., and Bret, J. (1969). Diagnosis and treatment of vascular malformations of the spinal cord. Journal of Neurosurgery, 30, 436-445.

Ommaya, A. K., Di Chiro, G., and Doppman, J. (1969). Ligation of arterial supply in the treatment of spinal cord arteriovenous malformations. Journal of Neurosurgery, 30, 679-692.

Shephard, R. H. (1963). Observations on intradural spinal angioma: treatment by excision. Neurochirurgia (Stuttgart), 6, 58-74.

Shephard, R. H. (1965). Some new concepts in intradural spinal angioma. Rivista di Patologia Nervosa e Mentale, 86, 276-283. 